\title{
Prevalence of chronic obstructive pulmonary disease and variation in risk factors across four geographically diverse resource-limited settings in Peru
}

Devan Jaganath ${ }^{1,2}$, J Jaime Miranda ${ }^{3,4}$, Robert H Gilman², Robert A Wise ${ }^{1}$, Gregory B Diette ${ }^{1}$, Catherine H Miele', Antonio Bernabe-Ortiz ${ }^{3}$, William Checkley ${ }^{1 *}$ and CRONICAS Cohort Study Group

\begin{abstract}
Background: It is unclear how geographic and social diversity affects the prevalence of chronic obstructive pulmonary disease (COPD). We sought to characterize the prevalence of COPD and identify risk factors across four settings in Peru with varying degrees of urbanization, altitude, and biomass fuel use.

Methods: We collected sociodemographics, clinical history, and post-bronchodilator spirometry in a randomly selected, age-, sex- and site-stratified, population-based sample of 2,957 adults aged $\geq 35$ years (median age was 54.8 years and $49.3 \%$ were men) from four resource-poor settings: Lima, Tumbes, urban and rural Puno. We defined COPD as a post-bronchodilator $\mathrm{FEV}_{1} / \mathrm{FVC}<70 \%$.

Results: Overall prevalence of COPD was $6.0 \%$ (95\% CI 5.1\%-6.8\%) but with marked variation across sites: $3.6 \%$ in semi-urban Tumbes, $6.1 \%$ in urban Puno, $6.2 \%$ in Lima, and $9.9 \%$ in rural Puno $(p<0.001)$. Population attributable risks (PARs) of COPD due to smoking $\geq 10$ pack-years were less than $10 \%$ for all sites, consistent with a low prevalence of daily smoking (3.3\%). Rather, we found that PARs of COPD varied by setting. In Lima, for example, the highest PARs were attributed to post-treatment tuberculosis (16\% and 22\% for men and women, respectively). In rural Puno, daily biomass fuel for cooking among women was associated with COPD (prevalence ratio 2.22, 95\% CI 1.02-4.81) and the PAR of COPD due to daily exposure to biomass fuel smoke was $55 \%$.

Conclusions: The burden of COPD in Peru was not uniform and, unlike other settings, was not predominantly explained by tobacco smoking. This study emphasizes the role of biomass fuel use, and highlights pulmonary tuberculosis as an often neglected risk factor in endemic areas.
\end{abstract}

Keywords: COPD, Peru, Respiratory disease, Chronic disease, Risk factors, Population studies, Biomass fuels

\section{Introduction}

The chronic disease epidemic has placed a large burden on morbidity and mortality in low and middle-income countries. The 2010 Global Burden of Disease study indicated that $54 \%$ of all disability-adjusted life years lost worldwide were attributed to non-communicable, chronic diseases [1]. Chronic obstructive pulmonary disease (COPD), characterized by lower airway inflammation

\footnotetext{
* Correspondence: wcheckl1@jhmi.edu

'Division of Pulmonary and Critical Care, School of Medicine, Johns Hopkins University, 1800 Orleans Ave Suite 9121, Baltimore, MD 21205, USA Full list of author information is available at the end of the article
}

and damage that impairs airflow, is the third leading cause of death worldwide, with a global prevalence estimate of $10 \%[2,3]$. Risk factors for COPD reported in the literature include smoking, outdoor pollution, indoor pollution, occupational dust exposure, asthma, past history of tuberculosis, and genetics [4-6].

Low- and middle-income countries currently share the greatest proportion of chronic respiratory disease worldwide $[7,8]$. Management guidelines and public health efforts specific to these settings are critical to prevention and care for COPD [9]. However, healthcare infrastructure for COPD surveillance and management in resource- 
limited settings are lacking [7]. In addition, the PLATINO and BOLD studies demonstrated substantial geographic variation in COPD prevalence, and the PURE study similarly found that lung function differed greatly by region $[6,10]$ This heterogeneity underscores the importance of investigating local factors that shape the burden of COPD, especially in resource-limited settings that contain considerable diversity in culture, socioeconomic status, and environment.

In Latin America, the PLATINO and PREPOCOL studies assessed the burden of COPD and highlighted risk factors such as tobacco smoking across their study settings [11-13]. However, there is a critical gap in our understanding of COPD across diverse geographical and social settings. Peruvians live in densely populated urban areas as well as rural village settings, along the coast and in the Andes Mountains, and we sought to characterize variation in prevalence and risk factors for COPD.

\section{Methods \\ Setting}

The CRONICAS study is a longitudinal, population-based study aimed to determine the prevalence of chronic pulmonary and cardiovascular diseases across four disparate regions in Peru. The study has been described in detail elsewhere [14] and involved collection of sociodemographic and clinical data from adults aged $\geq 35$ years in four diverse populations in Peru. The four settings under study varied based on degrees of urbanization, living at high altitude, prevalence of daily biomass fuel use. Pampas de San Juan de Miraflores is a dense, urbanized community 25 kilometers south of central Lima and consists primarily of Andean immigrants. Tumbes is a semi-urban, sea-level community in northern Peru within an agrarian setting and little to no vehicular traffic. Puno is a southwestern city in the Andes, located on the shores of Lake Titicaca at 3,825 meters above sea-level. Within Puno there were two separate sites: an urban setting located at the city center and a rural setting made up of inhabitants from surrounding communities [15].

\section{Design}

We enrolled an age (35-44, 45-54, 55-64 and $\geq 65$ years), sex and site stratified sample of eligible subjects. Recruitment began in September 2010 and was conducted until about 1,000 participants with complete information per site were enrolled. Only one participant per household was enrolled. In Puno, we stratified recruitment to include 500 participants each from the urban and rural settings. Inclusion criteria were age $\geq 35$ years, a full-time resident in the specified setting, and capacity to understand procedures and consent to the study. Exclusion criteria were pregnancy, physical disability that prevented measurement of blood pressure or anthropometry, or active pulmonary tuberculosis. All participants provided verbal informed consent after our research team read the entire informed consent document to them and any questions were answered. Informed consents were verbal because of high illiteracy rates. The study was approved by the Institutional Review Boards of Universidad Peruana Cayetano Heredia and A.B. PRISMA, in Lima, Peru, and the Johns Hopkins Bloomberg School of Public Health in Baltimore, USA.

\section{Data collection}

Participants responded to a questionnaire on sociodemographics, smoking history, respiratory symptoms, past medical history, and family history of disease. A detailed questionnaire also evaluated frequency and duration of cooking with biomass fuels. Field workers measured weight and height in triplicate. Spirometry was conducted using the Easy-On-PC spirometer (ndd, Zurich, Switzerland) before and after $200 \mathrm{mcg}$ of inhaled salbutamol via a spacer. Trained technicians measured pre- and post-bronchodilator spirometry in participants following joint American Thoracic Society and European Respiratory Society (ATS/ERS) guidelines [16]. We adapted a standardized grading system for quality control, review and interpretation [17]. Participants with low quality spirometry were asked to repeat the test on another day for a total of three attempts. Overall, 96\% of all tests achieved an acceptable result and 95\% met ATS/ERS criteria.

\section{Definitions}

We defined COPD according to the Global initiative for chronic Obstructive Lung Disease (GOLD) criteria as a post-bronchodilator $\mathrm{FEV}_{1} / \mathrm{FVC}<70 \%$ [18]. We used percent-predicted post-bronchodilator $\mathrm{FEV}_{1}$ values to assess severity by GOLD staging. Since there are no established reference equations for Peruvians, we utilized both the NHANES III Mexican-Americans [19] and the Global Lungs Initiative (GLI) mixed ethnic population equations [20]. In a sensitivity analysis, we also defined COPD as post-bronchodilator $\mathrm{FEV}_{1} / \mathrm{FVC}$ less than the lower limit of normal by age and sex according to GLI mixed ethnic population equations [20]. We defined a post-bronchodilator response as an improvement of greater than $12 \%$ and $200 \mathrm{~mL}$ in post-bronchodilator vs. pre-bronchodilator forced expiratory volumes. We defined high altitude as either living in urban or rural Puno versus sea level as either living in Lima or Tumbes. We derived a wealth index based on assets, household facilities and household income [21].

\section{Biostatistical methods}

The primary objectives of this analysis were to estimate the prevalence of COPD and identify variation in risk factors across our settings. We estimated the prevalence of COPD and corresponding 95\% confidence intervals 
(CI) by site using standard methods. We compared baseline characteristics and spirometry results across sites using chi-squared or Fisher exact tests for categorical variables and Wilcoxon rank sum or Kruskal-Wallis tests for continuous variables. We used sex-stratified multivariable Poisson regressions [22] to model the prevalence of COPD as a function of age, living at high altitude, degree of urbanization, smoking for at least 10 pack-years, tertiles of wealth index, history of posttreatment pulmonary tuberculosis, history of asthma, and daily use of biomass fuels for cooking. We used the Huber-White method to correct the variance-covariance matrix for correlated responses by site [23]. We did not include indicator variables for site as fixed effects in the multivariable regression model because of collinearity with selected environmental risk factors (Table 1). Population attributable risks for COPD due to risk factors were calculated as $P A R=\frac{p(P R-1)}{1+p(P R-1)}$, where $\mathrm{p}$ was the prevalence of exposure and PR was the adjusted prevalence ratio obtained from multivariable Poisson regression. Twenty-seven participants with missing values $(<1 \%)$ of the 2,957 were excluded from multivariable analysis. In an ancillary analysis, we assessed inter-test reliability for severity staging when using NHANES III vs. GLI percent predicted values both by percent agreement and the kappa statistic. Analyses were performed in STATA 12 (StataCorp, College Station, Texas, USA) and R (www.r-project.org).

\section{Results}

\section{Participant characteristics}

We enrolled 4,325 participants of whom 3,601 (83\%) had complete questionnaires (Figure 1). In total, 2,957 participants had complete spirometry data. We did not identify differences in age $(p=0.72)$, sex $(p=0.15)$, daily smoking $(\mathrm{p}=0.80)$, self-reported history of post-treatment pulmonary tuberculosis $(\mathrm{p}=0.88)$ and asthma $(\mathrm{p}=0.25)$ or biomass fuel use $(p=0.22)$ between participants with and without spirometry data in an analysis adjusted for site.

Among the 2,957 participants, median age was 54.8 years and $49.3 \%$ were men (Table 2). Daily smoking was low at

Table 1 Selected environmental risk factors by setting

\begin{tabular}{llll}
\hline Setting & Urbanization & $\begin{array}{l}\text { Daily use of } \\
\text { biomass fuels }\end{array}$ & Altitude \\
\hline Lima & Urban & Rare & Sea level \\
Tumbes & Semi-urban & Moderately prevalent & Sea level \\
Puno, urban & Urban & Rare & $\begin{array}{l}3,825 \text { meters above } \\
\text { sea level }\end{array}$ \\
& & & $\begin{array}{l}3,825 \text { meters above } \\
\text { suno, rural }\end{array}$ \\
& Rural & Highly prevalent & \\
\hline
\end{tabular}

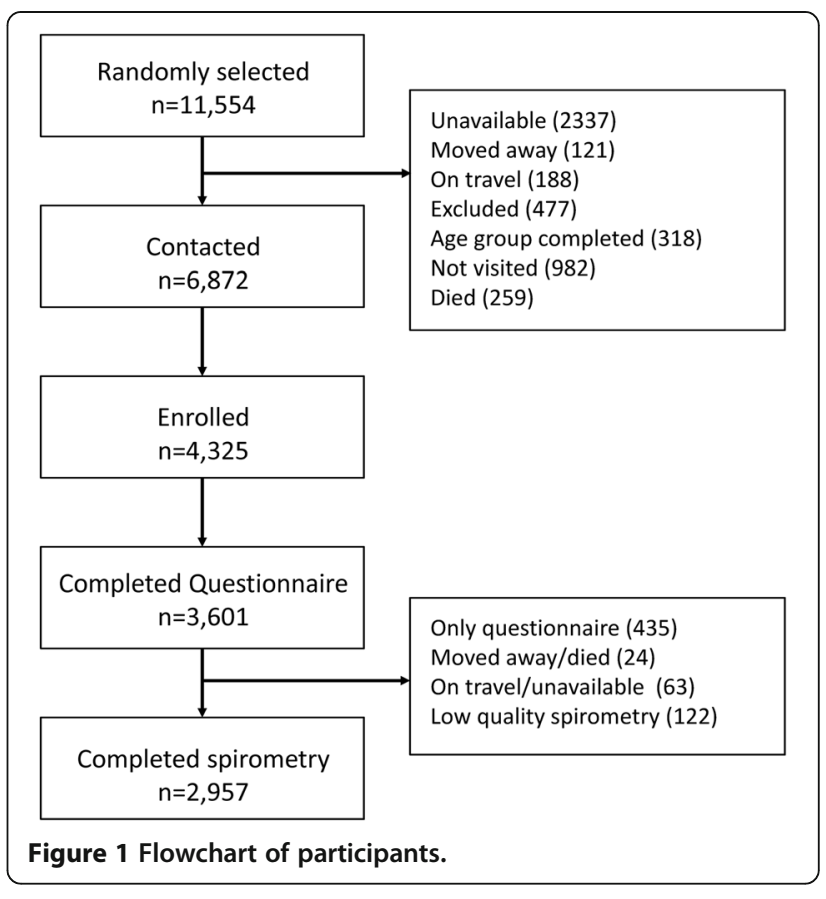

$3.3 \%$ across all sites, and ranged from $0.2 \%$ in rural Puno to $5.6 \%$ in Tumbes $(\mathrm{p}<0.001)$. Median pack-years among smokers was 0.2 (IQR 0.01-1.53). When stratified by sex, we found that $79(5.5 \%)$ men reported smoking daily compared to only $18(1.2 \%)$ women $(\mathrm{p}<0.001)$. Overall, $2.9 \%$ of participants reported a history of post-treatment pulmonary tuberculosis and 3.9\% reported a history of asthma. Participants in Lima reported having the highest prevalences of post-treatment pulmonary tuberculosis and asthma. Eight $(0.4 \%)$ individuals reported having a family history of COPD.

Non-urban settings had the highest proportions of biomass fuel use: $\geq 97 \%$ of participants in rural Puno reported that biomass fuels were used daily for cooking in their household, and 91\% reported cooking indoors. A total of $23 \%$ reported daily biomass fuel use in Tumbes, but $53 \%$ reported cooking indoors. Women were more likely to be the household cook: 1,432 (95.7\%) reported that they cooked vs. $862(59.4 \%)$ males ( $<0.001)$.

\section{Variation in lung function measurements}

We compared post-bronchodilator lung function across sites in both men (Table 3) and women (Table 4). Living at high altitude (urban or rural Puno) vs. at sea level (Lima or Tumbes) was associated with having higher average $\mathrm{FEV}_{1}$ values in both males $(3.5 \mathrm{~L}$ vs. $3.3 \mathrm{~L}$; p $<0.001$ ) and females (2.4 L vs. $2.3 \mathrm{~L} ; \mathrm{p}<0.001)$, higher average FVC values in both males $(4.4 \mathrm{~L}$ vs. $4.1 \mathrm{~L} ; \mathrm{p}<0.001)$ and females (3.0 L vs. $2.7 \mathrm{~L} ; \mathrm{p}<0.001)$, but lower average $\mathrm{FEV}_{1} / \mathrm{FVC}$ values in both males $(78.0 \%$ vs. $80.2 \%$; $\mathrm{p}<$ $0.001)$ and females (79.9\% vs. $82.8 \%$; $<0.001)$. 
Table 2 Participant characteristics across four sites in Peru (p-values calculated using Kruskal-Wallis tests for continuous variables, and chi-squared or Fisher exact tests for categorical variables)

\begin{tabular}{|c|c|c|c|c|c|c|}
\hline & $\begin{array}{l}\text { Lima } \\
998(33.8)\end{array}$ & $\begin{array}{l}\text { Urban Puno } \\
507 \text { (17.2) }\end{array}$ & $\begin{array}{l}\text { Rural Puno } \\
506(17.1)\end{array}$ & $\begin{array}{l}\text { Tumbes } \\
946(32.0)\end{array}$ & $\begin{array}{l}\text { Overall } \\
2957\end{array}$ & $P$ \\
\hline Age in years, median (IQR) & $54.7(45.5,64.0)$ & $54.8(44.9,64.5)$ & $54.8(45.1,63.9)$ & $54.9(45.0,64.8)$ & $54.8(45.2,64.3)$ & 0.87 \\
\hline Number of males (\%) & $492(49.3)$ & $250(49.3)$ & $240(47.4)$ & $475(50.2)$ & $1457(49.3)$ & 0.80 \\
\hline Height in m, median (IQR) & 1.54. $(1.49,1.61)$ & $1.57(1.50,1.63)$ & $1.55(1.49,1.62)$ & $1.58(1.52,1.65)$ & $1.56(1.50,1.63)$ & $<0.001$ \\
\hline $\mathrm{BMI}>30 \mathrm{~kg} / \mathrm{m}^{2}, \mathrm{n}(\%)$ & $324(32.5)$ & $133(26.4)$ & $54(10.8)$ & $299(31.6)$ & $810(27.5)$ & $<0.001$ \\
\hline Daily smoking, n (\%) & $32(3.2)$ & $11(2.2)$ & $1(0.2)$ & $53(5.6)$ & $97(3.3)$ & $<0.001$ \\
\hline Rural origin, $\mathrm{n}(\%)$ & $510(51.2)$ & $103(20.5)$ & $481(96.4)$ & $285(30.2)$ & $1379(46.9)$ & $<0.001$ \\
\hline \multicolumn{7}{|l|}{ Wealth index, n (\%) } \\
\hline Low & $119(11.9)$ & $120(23.9)$ & $356(70.4)$ & $307(32.5)$ & $902(30.6)$ & $<0.001$ \\
\hline Middle & $366(36.7)$ & $129(25.7)$ & $136(26.9)$ & $387(40.9)$ & $1018(34.5)$ & \\
\hline High & $513(51.4)$ & $254(50.5)$ & $14(2.8)$ & $252(26.6)$ & $1033(35.0)$ & \\
\hline \multicolumn{7}{|l|}{ Exposures, $\mathrm{n}(\%)$} \\
\hline Daily use of biomass fuels for cooking & $61(6.1)$ & $25(5.0)$ & $483(96.6)$ & $221(23.4)$ & $790(26.8)$ & $<0.001$ \\
\hline Cooks indoors & $573(57.8)$ & $436(86.7)$ & $453(90.8)$ & $497(53.0)$ & $1959(66.8)$ & $<0.001$ \\
\hline \multicolumn{7}{|l|}{ Clinical, (\%) } \\
\hline History of tuberculosis & $69(6.9)$ & $3(0.6)$ & $7(1.4)$ & $7(0.7)$ & $86(2.9)$ & $<0.001$ \\
\hline History of asthma & $82(8.2)$ & $13(2.6)$ & $3(0.6)$ & $16(1.7)$ & $114(3.9)$ & $<0.001$ \\
\hline Family History of asthma & $146(24.7)$ & $18(3.6)$ & $8(1.6)$ & $51(7.9)$ & $223(10.0)$ & $<0.001$ \\
\hline Family History of COPD & $4(0.7)$ & $4(0.8)$ & 0 & 0 & $8(0.4)$ & 0.04 \\
\hline
\end{tabular}

\section{Variation in COPD prevalence}

The overall prevalence of COPD was $6 \%$ with marked variation by sex and across sites. When stratified by sex, we found that $123(8.4 \%)$ men and 54 (3.6\%) women had COPD ( $\mathrm{p}<0.001)$. Across sites, prevalence ranged from $3.6 \%$ in Tumbes to $9.9 \%$ in rural Puno (Table 5). Participants in urban Puno had a similar prevalence of COPD than did those in Lima $(p=1.00)$ but a lower prevalence than participants in rural Puno $(\mathrm{p}=0.04)$. This trend was similar for both men and women. Staging by GOLD criteria showed that the majority of cases were either Stage I or II and similar across sites, regardless of GLI mixed ethnic population or NHANES III Mexican American reference equations $(93.8 \%$ agreement, kappa $=0.85)$. The only five severe stage cases of COPD (i.e., GOLD stage III) occurred in Lima and Tumbes, and all were male. We also found that post-bronchodilator response (i.e., reversibility) did not differ for males and females across sites among

Table 3 Median and interquartile range of post-bronchodilator lung function values in men using the Global Lungs Function Initiative (GLI) mixed ethnic population and Hankinson NHANES III Mexican-American reference equations (p-values calculated using Kruskal-Wallis tests)

\begin{tabular}{|c|c|c|c|c|c|}
\hline & Lima $(n=492)$ & Urban Puno $(n=250)$ & Rural Puno $(n=240)$ & Tumbes $(n=475)$ & $\mathbf{P}$ \\
\hline FEV $_{1}(\mathrm{~L})$ & $3.4(2.9-3.7)$ & $3.5(3.0-4.0)$ & $3.5(2.9-3.9)$ & $3.2(2.8-3.6)$ & $<0.001$ \\
\hline FVC (L) & $4.2(3.7-4.7)$ & $4.4(3.8-5.1)$ & $4.4(3.9-5.0)$ & $4.0(3.4-4.4)$ & $<0.001$ \\
\hline $\mathrm{FEV}_{1} /$ height $^{2}\left(\mathrm{~L} / \mathrm{m}^{2}\right)$ & $1.3(1.1-1.4)$ & $1.3(1.1-1.4)$ & $1.3(1.1-1.5)$ & $1.2(1.0-1.3)$ & $<0.001$ \\
\hline FVC/height ${ }^{2}\left(\mathrm{~L} / \mathrm{m}^{2}\right)$ & $1.6(1.4-1.8)$ & $1.7(1.5-1.9)$ & $1.7(1.5-1.9)$ & $1.5(1.3-1.6)$ & $<0.001$ \\
\hline $\mathrm{FEV}_{1} / \mathrm{FVC}(\%)$ & $80.0(75.4-83.4)$ & $78.4(74.9-82.3)$ & $77.8(73.6-81.0)$ & $80.6(77.4-84.0)$ & $<0.001$ \\
\hline \multicolumn{6}{|c|}{ Percent Predicted FEV $_{1}(\%)$} \\
\hline GLI & $117.9(107.5-129.8)$ & 119.9 (109.9-130.2) & $121.7(111.5-133.9)$ & $107.7(97.7-117.5)$ & $<0.001$ \\
\hline NHANES III & $113.3(102.0-124.7)$ & $114.6(105.2-124.2)$ & $117.0(106.7-129.0)$ & $102.4(92.6-112.0)$ & $<0.001$ \\
\hline \multicolumn{6}{|c|}{ Percent Predicted FVC (\%) } \\
\hline GLI & $120.1(108.9-130.5)$ & $123.0(112.8-134.3)$ & $126.2(114.4-139.3)$ & $107.7(98.3-116.0)$ & $<0.001$ \\
\hline NHANES III & $109.7(99.8-119.5)$ & $112.3(104.7-123.3)$ & $116.1(105.6-128.1)$ & $98.7(90.1-107.0)$ & $<0.001$ \\
\hline
\end{tabular}


Table 4 Median and interquartile range of post-bronchodilator lung function values in women using the Global Lungs Function Initiative (GLI) mixed ethnic population and Hankinson NHANES III Mexican-American reference equations (p-values calculated using Kruskal-Wallis tests)

\begin{tabular}{|c|c|c|c|c|c|}
\hline & Lima $(n=506)$ & Urban Puno ( $\mathrm{n}=257$ ) & Rural Puno ( $n=266)$ & Tumbes $(n=471)$ & $\mathbf{P}$ \\
\hline $\mathrm{FEV}_{1}(\mathrm{~L})$ & $2.3(2.0-2.6)$ & $2.4(2.0-2.8)$ & $2.4(2.0-2.8)$ & $2.2(1.9-2.5)$ & $<0.001$ \\
\hline FVC (L) & $2.8(2.4-3.2)$ & $3.0(2.5-3.5)$ & $3.0(2.5-3.5)$ & $2.6(2.3-2.9)$ & $<0.001$ \\
\hline $\mathrm{FEV}_{1} /$ height $^{2}\left(\mathrm{~L} / \mathrm{m}^{2}\right)$ & $1.0(0.9-1.2)$ & $1.1(0.9-1.2)$ & $1.1(0.9-1.2)$ & $0.9(0.8-1.1)$ & $<0.001$ \\
\hline FVC/height $^{2}\left(\mathrm{~L} / \mathrm{m}^{2}\right)$ & $1.3(1.1-1.4)$ & $1.3(1.1-1.5)$ & $1.3(1.2-1.5)$ & $1.1(1.0-1.3)$ & $<0.001$ \\
\hline $\mathrm{FEV}_{1} / \mathrm{FVC}(\%)$ & $82.7(79.3-85.3)$ & $80.5(77.0-83.6)$ & $79.6(75.6-82.5)$ & $83.0(79.7-86.1)$ & $<0.001$ \\
\hline \multicolumn{6}{|c|}{ Percent predicted $\mathrm{FEV}_{1}(\%)$} \\
\hline GLI & $112.0(102.1-123.7)$ & $115.2(106.1-126.5)$ & $113.9(102.3-126.0)$ & $103.1(93.8-112.0)$ & $<0.001$ \\
\hline NHANES III & $106.2(96.9-117.2)$ & $110.4(100.7-119.7)$ & $107.5(96.5-118.4)$ & $96.5(88.5-105.5)$ & $<0.001$ \\
\hline \multicolumn{6}{|c|}{ Percent predicted FVC (\%) } \\
\hline GLI & $111.7(100.3-122.1)$ & $119.2(106.4-129.2)$ & $116.9(104.7-128.3)$ & $101.1(93.2-109.9)$ & $<0.001$ \\
\hline NHANES III & $103.4(92.8-113.0)$ & 110.5 (98.3-119.1) & 107.6 (96.7-118.4) & $93.1(85.5-100.8)$ & $<0.001$ \\
\hline
\end{tabular}

those with COPD. However, there was significant variation across sites for individuals without COPD and rural Puno had the highest proportion of participants with a postbronchodilator response.

When using the lower limit of normal for $\mathrm{FEV}_{1} / \mathrm{FVC}$ based on GLI reference equations, we found that there were 142 cases of COPD (prevalence of 4.8\%; 95\% CI 4.0 to 5.6). By site, the prevalence was 57 (5.7\%) in Lima, 25 (4.9\%) in urban Puno, 43 (8.5\%) in rural Puno, and 17 (1.8\%) in Tumbes. Overall, this corresponded to $97 \%$ agreement with the fixed ratio definition, and a kappa of 0.69 .

\section{Risk factors associated with COPD}

Single variable analysis suggested that age, sex, altitude, smoking, urbanization, socioeconomic status, post-treatment tuberculosis, asthma, and daily biomass fuel use may be associated with COPD prevalence (Table 6). In sex-stratified multivariable analyses (Table 7), older vs. younger individuals and those who lived at a higher altitude vs. at sea level had greater prevalence of COPD. Moreover, both a history of post-treatment tuberculosis and asthma were positively associated with COPD. Smoking for at least 10 pack-years was associated with COPD in males, and was marginally significant in females. We found that females but not males who lived in a rural setting were more likely to have COPD compared to an urban setting, while living in semi-urban region was associated with a decreased likelihood of COPD compared to an urban setting for both sexes.

Population attributable risks of COPD

We calculated PARs of COPD across sites and by sex due to daily biomass fuel use, smoking at least 10 pack-years, post-

Table 5 Prevalence of COPD across four sites in Peru using the Global Lungs Function Initiative (GLI) mixed ethnic population and Hankinson NHANES III Mexican-American reference equations (p-values calculated using chi-squared or Fisher exact tests)

\begin{tabular}{|c|c|c|c|c|c|c|}
\hline & $\begin{array}{l}\text { Lima } \\
\text { (n = 998) }\end{array}$ & $\begin{array}{l}\text { Urban Puno } \\
(n=507)\end{array}$ & $\begin{array}{l}\text { Rural Puno } \\
(n=506)\end{array}$ & $\begin{array}{l}\text { Tumbes } \\
\text { (n = 946) }\end{array}$ & Overall & $P$ \\
\hline COPD prevalence $(95 \% \mathrm{CI})$ & $6.2(4.7-7.7)$ & $6.1(4.0-8.2)$ & $9.9(7.3-12.5)$ & $3.6(2.4-4.8)$ & $6.0(5.1-6.8)$ & $<0.001$ \\
\hline \multicolumn{7}{|l|}{ GOLD class by GLI, n (\%) } \\
\hline 1 & $43(69.4)$ & $26(83.9)$ & $38(76.0)$ & $21(61.7)$ & $128(72.3)$ & \multirow[t]{3}{*}{0.29} \\
\hline II & $16(25.8)$ & $5(16.1)$ & $12(24.0)$ & $11(32.4)$ & $44(24.9)$ & \\
\hline III & $3(4.8)$ & 0 & 0 & $2(5.9)$ & $5(2.8)$ & \\
\hline \multicolumn{7}{|l|}{ GOLD class by NHANES III, n (\%) } \\
\hline I & $42(67.7)$ & $24(77.4)$ & $38(76.0)$ & $19(55.9)$ & $123(69.5)$ & \multirow[t]{3}{*}{0.26} \\
\hline II & $17(27.4)$ & $7(22.6)$ & $12(24.0)$ & $13(38.2)$ & $49(27.8)$ & \\
\hline III & $3(4.8)$ & 0 & 0 & $2(5.9)$ & $5(2.8)$ & \\
\hline Post-bronchodilator response in COPD, n (\%) & $22(36 \%)$ & $8(26 \%)$ & $13(26 \%)$ & $9(27 \%)$ & $52(29 \%)$ & 0.63 \\
\hline Post-bronchodilator response in non-COPD, $\mathrm{n}(\%)$ & $99(11 \%)$ & $57(12 \%)$ & $78(17 \%)$ & $73(8 \%)$ & $307(11 \%)$ & $<0.001$ \\
\hline
\end{tabular}


Table 6 Single variable factors associated with COPD prevalence across four sites in Peru $(n=2957)$

\begin{tabular}{llll}
\hline & Prevalence ratio & $\mathbf{9 5 \%} \mathbf{C l}$ \\
\hline Age (per 10 years) & 1.93 & $1.71-2.17$ & $\mathbf{P}$ \\
Male vs. Female Sex & 2.35 & $1.61-3.42$ & $<0.001$ \\
Height (cm) & 1.01 & $0.99-1.02$ & 0.001 \\
High Altitude vs. sea-level & 1.61 & $0.92-2.82$ & 0.10 \\
$\mathbf{1} \mathbf{1 0}$ pack-years of smoking & 2.51 & $1.65-3.80$ & \\
Urbanization & & & \\
$\quad$ Urban & 1.00 & $0.57-0.58$ \\
$\quad$ Semi-Urban & 0.58 & $1.56-1.59$ \\
$\quad$ Rural & 1.57 & $3.09-5.88$ \\
Post-treatment pulmonary tuberculosis & 4.27 & $1.59-3.88$ \\
Asthma & 2.49 & $1.25-2.25$ \\
Biomass use at least once daily & 1.68 & $<0.001$ \\
Wealth Index & & $<0.001$ \\
$\quad$ Low & 1.00 & $<0.001$ \\
Middle & 0.81 & $0.50-1.30$ \\
High & 0.53 & $0.33-0.87$ \\
\hline
\end{tabular}

treatment pulmonary tuberculosis and asthma (Figure 2). Daily biomass fuel use notably increased PAR of COPD among women based on degree of urbanization, with $23 \%$ in semi-urban Tumbes and $55 \%$ in rural Puno. PAR of COPD due to smoking $\geq 10$ pack years was less than $10 \%$ for all sites, and was greatest for men in Tumbes at $7 \%$. Post-treatment pulmonary tuberculosis contributed the most to COPD in Lima, where PAR of COPD was $16 \%$ in men and $23 \%$ in women. PAR of COPD due to asthma was similarly highest in Lima, with $6 \%$ in men and $12 \%$ in women.

\section{Discussion}

In this multi-center, population-based study of adult participants in Peru, we found considerable variation in lung function and prevalence of COPD among four resource-poor sites with varying degrees of urbanization, altitude, and biomass fuel use. While daily smoking prevalence was low across sites, population attributable risks of COPD suggest that daily biomass fuel use contributed to an important proportion of COPD in rural settings, whereas a history of post-treatment pulmonary tuberculosis and asthma were important risk factors in

Table 7 Multivariable regression of risk factors associated with COPD prevalence in Peru, stratified by sex $(n=2930)$

\begin{tabular}{|c|c|c|c|c|c|c|}
\hline & \multicolumn{3}{|l|}{ Males $(n=1443)$} & \multicolumn{3}{|c|}{ Females $(n=1487)$} \\
\hline & Prevalence ratio & $95 \% \mathrm{Cl}$ & $\mathbf{P}$ & Prevalence ratio & $95 \% \mathrm{Cl}$ & $P$ \\
\hline Age (per 10 years) & 1.65 & $1.42-1.92$ & $<0.001$ & 2.51 & $1.86-3.38$ & $<0.001$ \\
\hline High altitude vs. sea-level & 1.13 & $1.06-1.21$ & $<0.001$ & 1.44 & $1.05-1.99$ & 0.02 \\
\hline$\geq 10$ pack-years of smoking & 1.80 & $1.40-2.32$ & $<0.001$ & 2.39 & $0.59-9.63$ & 0.22 \\
\hline \multicolumn{7}{|l|}{ Urbanization } \\
\hline Urban & 1.00 & & & 1.00 & & \\
\hline Semi-Urban & 0.52 & $0.43-0.64$ & $<0.001$ & 0.66 & $0.53-0.82$ & $<0.001$ \\
\hline Rural & 1.01 & $0.74-1.37$ & 0.97 & 1.71 & $1.47-1.99$ & $<0.001$ \\
\hline Post-treatment pulmonary tuberculosis & 3.12 & $2.02-4.83$ & $<0.001$ & 7.02 & $3.63-13.59$ & $<0.001$ \\
\hline Asthma & 2.16 & $1.11-4.23$ & 0.02 & 2.30 & $1.12-4.72$ & 0.02 \\
\hline Biomass use at least once daily & 1.08 & $0.55-2.11$ & 0.82 & 2.22 & $1.02-4.81$ & 0.04 \\
\hline \multicolumn{7}{|l|}{ Wealth index } \\
\hline Low & 1.00 & & & 1.00 & & \\
\hline Middle & 1.02 & $0.69-1.52$ & 0.91 & 1.78 & $0.52-6.00$ & 0.36 \\
\hline High & 0.68 & $0.39-1.19$ & 0.18 & 1.44 & $0.54-3.86$ & 0.47 \\
\hline
\end{tabular}




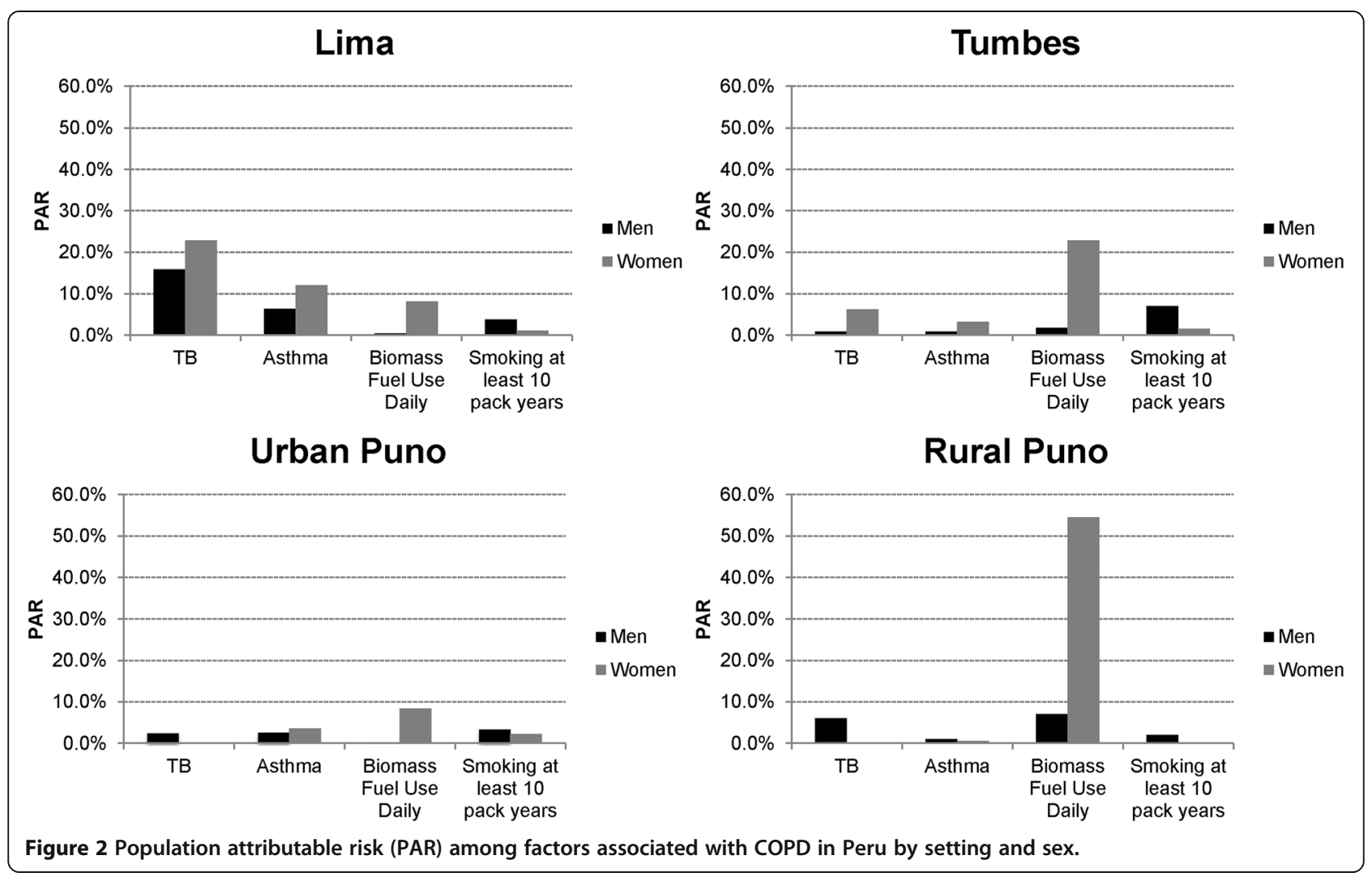

urban settings such as Lima. Our study also highlights the importance of post-treatment pulmonary tuberculosis, a prevalent disease with worldwide distribution, as a possible neglected risk factor for COPD in endemic areas.

The prevalence of COPD in Peru was 25\% to $70 \%$ lower relative to multi-center studies in other countries $[3,11]$. In the BOLD study, the prevalence of COPD was $10.1 \%$ for moderate to severe (i.e., GOLD stage II or greater) in twelve sites from North America, Europe, Asia and Africa [3]. In the PLATINO study, the prevalence of COPD ranged from $7.8 \%$ to $19.7 \%$ in five cities from Brazil, Chile, Mexico, Uruguay and Venezuela [11]. In the PREPOCOL study, the prevalence of COPD was $8.9 \%$ across five Colombian cities at varying altitudes [13]. A possible reason for the low prevalence of COPD in our study is also the low prevalence of daily tobacco smoking: $3 \%$ were daily smokers, with a population attributable risk of COPD due to tobacco smoking of $<10 \%$ across all sites for both men and women. In comparison, every city in the PLATINO study had a current smoking prevalence of $>20 \%$ [24]. If smoking prevalence is low in Peru, this raised the question of what other determinants are associated with COPD, and what factors explained heterogeneity between sites. Utilizing within-country diversity, we evaluated this question to direct prevention and management efforts across settings.
Between our sites, we also found considerable variation in lung function and COPD prevalence. High altitude areas of urban and rural Puno had notably larger lung capacity as compared to sea level Lima or Tumbes, and supports past studies on physiological adaptation to high altitude $[25,26]$. Despite greater lung capacity and the lowest rates of smoking, $\mathrm{FEV}_{1} / \mathrm{FVC}$ was lower at higher altitude vs. sea level settings. The role of high altitude on COPD has been equivocal: investigators of the PLATINO study suggested that high altitude contributed to lower prevalence of COPD, whereas those of the PREPOCOL study found a higher prevalence of COPD at the high altitude sites of Colombia [11,13]. In both studies, the authors noted that changes in $\mathrm{FEV}_{1}$ and FVC among people who live at high altitude may affect classification of obstruction. We also found that high attitude vs. sea level was associated with a small but relatively greater increase in FVC compared to $\mathrm{FEV}_{1}$, which may lead to overestimation of COPD. At the same time, in the PLATINO and PREPOCOL studies, the highest altitude cities were Mexico City (2,250 meters above sea level) and Bogotá (2,640 meters above sea level), respectively, which are more urbanized than our high altitude setting in Puno $(3,825$ meters above sea level). Further research is required to investigate how altitude affects variation in COPD prevalence. 
In our analysis, we also found that rural residents in Puno primarily cooked indoors and used biomass fuel daily. Notably, they had a higher prevalence of COPD than participants in urban Lima or even urban Puno. Biomass fuel is associated with a chronic inflammatory response and ultimately pulmonary damage that increase the risk of COPD [27,28]. In addition to biomass fuel smoke exposure, multivariable analysis revealed that a history of post-treatment pulmonary tuberculosis and asthma were also associated with COPD, specifically in our urban settings. Population attributable risks of COPD between sites further demonstrated the importance of post-treatment pulmonary tuberculosis and asthma in the urban setting of Lima. Pulmonary tuberculosis is associated with lung scarring, bronchial stenosis and parenchymal damage that can promote airway obstruction in endemic areas $[4,29]$. In the BOLD, PLATINO and PREPOCOL studies, investigators also found a positive association between pulmonary tuberculosis and COPD $[5,13,29]$. Chronic asthma has been associated with irreversible airway obstruction over time, with more rapid decline in $\mathrm{FEV}_{1}$ [4]. For both post-treatment pulmonary tuberculosis and asthma, further work will need to identify how their pathogenesis of airway obstruction compares to other traditional risk factors for COPD such as tobacco smoking [4], while well-designed prospective studies are necessary to assess direction of causality.

We also found sex-specific risk factors for COPD, which suggests that men and women in our setting face different types and amounts of exposures that impact their likelihood of disease. Among men, increasing pack years of smoking was an important determinant of COPD. While smoking among women was also associated with COPD, the effect was not significant, and may be a consequence of the low number of women $(<2 \%)$ who smoked daily. The population attributable risk of COPD due to tobacco smoking was greatest in Tumbes, in particular among men where the local prevalence of smoking at least 10 pack-years was $10 \%$. Among women, biomass fuel use at least once daily was also associated with COPD. Men did not show this trend, and suggests that while all members of the household were exposed to biomass fuel smoke, men may have an overall reduced exposure as they are commonly not the primary cook. A systematic review found that rural women who used biomass fuels had greater odds of having COPD [30]. Similarly, we found the population attributable risk of COPD due to daily exposure to biomass fuel smoke was 55\% among women in rural Puno.

Our study has several strengths. First, our study is a population-based sample derived from four diverse geographical and social settings across Peru. Second, we collected extensive demographic, clinical, and behavioral data while conducting standardized pulmonary function tests to characterize COPD. Third, the low prevalence of tobacco smoking provided a unique opportunity for us to examine other risk factors associated with the prevalence of COPD. Our study also has some limitations. First, we were not powered to determine risk factors stratified by site. Second, we utilized two commonly used international reference equations to calculate the percent-predicted $\mathrm{FEV}_{1}$ and FVC $[19,20]$; however, the construction of these reference equations did not include Peruvians, which affect our estimation of severity categories. However, we found overall good consistency in the distributions of severity categories between the two reference equations. Third, self-reported history of COPD, post-treatment pulmonary tuberculosis or asthma has limitations compared to direct diagnostic evaluation and may be underestimated in those without access to care. Fourth, while sites varied in degree of urbanization and exposure to biomass fuel smoke and provided a gradient in ambient air pollution, personal air pollution exposure measurements would have provided a more quantitative comparison of differences. Finally, as a cross-sectional analysis, there are limitations in determining direction of causality for possible risk factors.

\section{Conclusion}

We found that both the prevalence of COPD and risk factors in Peru varied significantly across settings. Daily biomass fuel smoke exposure, particularly in rural sites, was an important cause for this heterogeneity, as compared to differences in tobacco smoking. At the same time, a history of respiratory disease including post-treatment pulmonary tuberculosis and asthma were important factors in urban centers. Overall, we have highlighted unique aspects of COPD across geographic settings in Peru, to better understand these determinants, guide future studies, and implement interventions to reduce the burden of COPD.

\section{Abbreviations}

COPD: Chronic obstructive pulmonary disease; FEV1: Forced expiratory volume in 1 second; FVC: Forced vital capacity; FEV 1 /FVC: Ratio of forced expiratory volume in 1 second to forced vital capacity; GOLD: Global initiative for chronic obstructive lung disease; GLl: Global Lungs Function Initiative; NHANES: National Health and Nutrition Examination Survey; $\mathrm{Cl}$ : Confidence interval.

\section{Competing interests}

The authors declare that they have no competing interests.

\section{Authors' contributions}

JJM, RHG and WC conceived, designed and supervised the overall study. JJM, $\mathrm{ABO}$ and WC coordinated and supervised fieldwork activities in Lima, Tumbes and Puno. DJ and WC developed the idea for this manuscript and wrote the first draft. DJ and WC led the statistical analysis. DJ, JJM, RHG, CHM, RAW GBD, ABO and WCH participated in writing of manuscript, provided important intellectual content and gave their final approval of the version submitted for publication. 


\section{Acknowledgments}

The authors are indebted to all participants who kindly agreed to participate in the study. Special thanks to all field teams for their commitment and hard work, especially to Lilia Cabrera, Rosa Salirrosas, Viterbo Aybar, Sergio Mimbela, and David Danz for their leadership in each of the study sites, as well as Marco Varela for data coordination.

\section{Funding}

This project has been funded in whole with Federal funds from the United States National Heart, Lung, and Blood Institute, National Institutes of Health, Department of Health and Human Services, under Contract No. HHSN268200900033C. William Checkley was further supported by a Pathway to Independence Award (ROOHL096955) from the National Heart, Lung and Blood Institute.

\section{Author details}

'Division of Pulmonary and Critical Care, School of Medicine, Johns Hopkins University, 1800 Orleans Ave Suite 9121, Baltimore, MD 21205, USA. ${ }^{2}$ Program in Global Disease Epidemiology and Control, Department of International Health, Bloomberg School of Public Health, Johns Hopkins University, Baltimore, USA. ${ }^{3}$ CRONICAS Center of Excellence for Chronic Diseases, Universidad Peruana Cayetano Heredia, Lima, Peru. ${ }^{4}$ Departamento de Medicina, Escuela de Medicina, Universidad Peruana Cayetano Heredia, Lima, Peru.

Received: 20 August 2014 Accepted: 27 February 2015

Published online: 18 March 2015

\section{References}

1. Murray CJ, Vos T, Lozano R, Naghavi M, Flaxman AD, Michaud C, et al. Disability-adjusted life years (DALYs) for 291 diseases and injuries in 21 regions, 1990-2010: a systematic analysis for the global burden of disease study 2010. Lancet. 2012;380:2197-223.

2. Lozano R, Naghavi M, Foreman K, Lim S, Shibuya K, Aboyans V, et al. Global and regional mortality from 235 causes of death for 20 age groups in 1990 and 2010: a systematic analysis for the global burden of disease study 2010. Lancet. 2012;380:2095-128.

3. Buist AS, McBurnie MA, Vollmer WM, Gillespie S, Burney P, Mannino DM, et al. International variation in the prevalence of COPD (The BOLD study): a population-based prevalence study. Lancet. 2007;370:741-50.

4. Eisner MD, Anthonisen N, Coultas D, Kuenzli N, Perez-Padilla R, Postma D, et al. An official American Thoracic Society public policy statement: Novel risk factors and the global burden of chronic obstructive pulmonary disease. Am J Respir Crit Care Med. 2010;182:693-718.

5. Hooper R, Burney P, Vollmer WM, McBurnie MA, Gislason T, Tan WC, et al. Risk factors for COPD spirometrically defined from the lower limit of normal in the BOLD project. Eur Respir J. 2012;39:1343-53.

6. Mannino DM, Buist AS. Global burden of COPD: risk factors, prevalence, and future trends. Lancet. 2007;370:765-73.

7. Bousquet J, Kiley J, Bateman ED, Viegi G, Cruz AA, Khaltaev N, et al. Prioritised research agenda for prevention and control of chronic respiratory diseases. Eur Respir J. 2010;36:995-1001.

8. Checkley W, Ghannem H, Irazola V, Kimaiyo S, Levitt NS, Miranda JJ, et al. Management of NCD in low- and middle-income countries. Glob Heart. 2014;9:431-43.

9. Aït-Khaled N, Enarson DA, Ottmani S, El Sony A, Eltigani M, Sepulveda R. Chronic airflow limitation in developing countries: burden and priorities. Int J Chron Obstruct Pulmon Dis. 2007;2:141-50.

10. Duong M, Islam S, Rangarajan S, Teo K, O'Byrne PM, Schünemann HJ, et al. Global differences in lung function by region (PURE): an international, community-based prospective study. Lancet Respir Med. 2013;1:599-609.

11. Menezes AM, Perez-Padilla R, Jardim JR, Muiño A, Lopez MV, Valdivia G, et al. Chronic obstructive pulmonary disease in five Latin American cities (the PLATINO study): a prevalence study. Lancet. 2005;366:1875-81.

12. Menezes AM, Jardim JR, Pérez-Padilla R, Camelier A, Rosa F, Nascimento O, et al. Prevalence of chronic obstructive pulmonary disease and associated factors: the PLATINO study in Sao Paulo, Brazil. Cad Saude Publica. 2005:21:1565-73.

13. Caballero A, Torres-Duque CA, Jaramillo C, Bolívar F, Sanabria F, Osorio P, et al. Prevalence of COPD in five Colombian cities situated at low, medium, and high altitude (PREPOCOL study). Chest. 2008;133:343-9.
14. Miranda JJ, Bernabe-Ortiz A, Smeeth L, Gilman RH, Checkley W, CRONICAS Cohort Study Group. Addressing geographical variation in the progression of non-communicable diseases in Peru: the CRONICAS cohort study protocol. BMJ Open. 2012;2(1):e000610.

15. Instituto Nacional de Estadística e Informática and ICF International. Peru DHS, 2012. Lima, Peru; 2013.

16. Miller MR, Hankinson J, Brusasco V, Burgos F, Casaburi R, Coates A, et al. Standardisation of spirometry. Eur Respir J. 2005;26:319-38.

17. Ferguson GT, Enright PL, Buist AS, Higgins MW. Office spirometry for lung health assessment in adults: a consensus statement from the national lung health education program. Chest. 2000;117:1146-61.

18. Pauwels RA, Buist AS, Calverley PM, Jenkins CR, Hurd SS, GOLD Scientific Committee. Global strategy for the diagnosis, management, and prevention of chronic obstructive pulmonary disease. Am J Respir Crit Care Med. 2012;163:1256-76

19. Hankinson JL, Odencrantz JR, Fedan KB. Spirometric reference values from a sample of the general U.S. population. Am J Respir Crit Care Med. 1999;159:179-87.

20. Quanjer PH, Stanojevic S, Cole TJ, Baur X, Hall GL, Culver BH, et al. Multi-ethnic reference values for spirometry for the 3-95-yr age range: the global lung function 2012 equations. Eur Respir J. 2012;40:1324-43.

21. Howe LD, Galobardes B, Matijasevich A, Gordon D, Johnston D, Onwujekwe O, et al. Measuring socio-economic position for epidemiological studies in low-and middle-income countries: a methods of measurement in epidemiology paper. Int J Epidemiol. 2012;41:871-86.

22. Barros AS, Hirakata VN. Alternatives for logistic regression in cross-sectional studies: an empirical comparison of models that directly estimate the prevalence ratio. BMC Med Res Methodol. 2003;3:21.

23. Williams RL. A note on robust variance estimation for cluster-correlated data Biometrics. 2000;56:645-6.

24. Menezes AM, Lopez MV, Hallal PC, Muiño A, Perez-Padilla R, Jardim JR, et al. Prevalence of smoking and incidence of initiation in the Latin American adult population: the PLATINO study. BMC Public Health. 2009;9:151.

25. Havryk AP, Gilbert M, Burgess KR. Spirometry values in Himalayan high altitude residents (Sherpas). Respir Physiol Neurobiol. 2002;132:223-32.

26. Rupert JL, Hochachka PW. The evidence for hereditary factors contributing to high altitude adaptation in Andean natives: a review. High Alt Med Biol. 2001;2:235-56

27. Torres-Duque C, Maldonado D, Pérez-Padilla R, Ezzati M, Viegi G, Forum of International Respiratory Studies (FIRS) Task Force on Health Effects of Biomass Exposure. Biomass fuels and respiratory diseases. Proc Am Thorac Soc. 2008;5:577-90.

28. Kurmi OP, Semple S, Simkhada P, Smith WC, Ayres J. COPD and chronic bronchitis risk of indoor air pollution from solid fuel: a systematic review and meta-analysis. Thorax. 2010;65:221-8.

29. Menezes AM, Hallal PC, Perez-Padilla R, Jardim JR, Muiño A, Lopez MV, et al. Tuberculosis and airflow obstruction: evidence from the PLATINO study in Latin America. Eur Respir J. 2007;30:1180-5.

30. Po JY, FitzGerald JM, Carlsten C. Respiratory disease associated with solid biomass fuel exposure in rural women and children: systematic review and meta-analysis. Thorax. 2011;66:232-9.

\section{Submit your next manuscript to BioMed Central and take full advantage of:}

- Convenient online submission

- Thorough peer review

- No space constraints or color figure charges

- Immediate publication on acceptance

- Inclusion in PubMed, CAS, Scopus and Google Scholar

- Research which is freely available for redistribution

Submit your manuscript at www.biomedcentral.com/submit

C) Biomed Central 